\title{
Determination of the Tenth and Half Value Layer Thickness of Concretes with Different Densities
}

\author{
A. AKKaş \\ Suleyman Demirel University Technology, Faculty Civil Engineering, 32260 Isparta, Turkey
}

\begin{abstract}
Half value layer (HVL) is the most frequently used quantitative factor for describing both the penetrating ability of specific radiations and the penetration through specific objects. The half value layers (HVL) and tenth value layers (TVL) are defined as the thickness of a shield or an absorber that reduces the radiation level by a factor of one-half and one tenth of the initial level, respectively. The concepts of HVL and TVL are widely used in shielding design. They are photon energy dependent, like the attenuation coefficient. HVL and TVL values provide useful information about the penetration of a specific radiation in a specific material. In this study, TVL and HVL thickness are calculated for concretes with different densities. For this purpose five types of concrete with different density ranges were selected, with densities between $600-1500 \mathrm{~kg} / \mathrm{m}^{3}$, called lightweight concrete, $1400-2000 \mathrm{~kg} / \mathrm{m}^{3}$, called semi lightweight concrete, $2000-2500 \mathrm{~kg} / \mathrm{m}^{3}$ called ordinary concrete, $2500-3000 \mathrm{~kg} / \mathrm{m}^{3}$, semi heavyweight concrete and 3000-4000 kg/m $\mathrm{m}^{3}$ called heavyweight concrete, respectively. For evaluated TVL and HVL thicknesses, the linear attenuation coefficients $\mu$, were determined from measurements, using a collimated beam of gamma rays from a Cobalt-60 source.
\end{abstract}

DOI: 10.12693/APhysPolA.129.770

PACS/topics: $78.20 . \mathrm{Ci}, 29.30 . \mathrm{Kv}, 34.50 . \mathrm{Bw}$

\section{Introduction}

Ionizing radiation has become a very important in our routine life, especially in medical applications. This radiation interacts with matter in two ways, by ionization and excitation. Absorbed radiation can cause biological damage in living tissues and DNA. The major principles of protection from external radiation sources are governed by four factors: time, distance, shielding and activity [1]. Shielding is the basic method for radiation protection. Intensity of gamma rays is attenuated exponentially. Therefore, theoretically it is not possible to attenuate the ionization radiation completely, although the dose rate can be reduced by any desired factor by an appropriate thickness of shielding. Thus, the half value layer, reduces dose rate to one-half of the initial dose, the tenth value layer, reduces dose rate to one-tenth of the initial dose rate [2].

The concrete used in building construction, is an important and widely used building material. Concrete is very efficient both in absorbing gamma rays and in slowing down fast neutrons by elastic and inelastic scattering, because it consists of mixture of hydrogen and other light nuclei and the nuclei of fairly high atomic number [3]. Besides the physical and mechanical properties of concretes, used in building construction, the radiation shielding properties should also be known. The thickness of any given material, at which $10 \%$ or $50 \%$ of the incident energy has been attenuated is known as the tenthvalue layer (TVL) and half value layer thickness (HVL),

\footnotetext{
*e-mail: ayseakkas@sdu.edu.tr
}

respectively. The TVL and HVL thicknesses are expressed in units of distance $(\mathrm{mm}$ or $\mathrm{cm})$. These are photon energy dependent, like the attenuation coefficient [4]. HVL and TVL values are the most frequently used quantitative raw factor for describing the penetrating ability of specific radiations through specific material [5]. In this study, TVL and HVL thicknesses are calculated for concretes with different densities. For this purpose concretes with densities in five different ranges were selected, densities between $600-1500 \mathrm{~kg} / \mathrm{m}^{3}$, called lightweight concrete (LC), $1400-2000 \mathrm{~kg} / \mathrm{m}^{3}$, called semi lightweight concrete (SLC), $2000-2500 \mathrm{~kg} / \mathrm{m}^{3}$, called ordinary concrete (OC), $2500-3000 \mathrm{~kg} / \mathrm{m}^{3}$ semi heavyweight concrete (SHC), 3000-4000 kg/m ${ }^{3}$ called heavyweight concrete (HC), respectively. For evaluated TVL and HVL thicknesses, the linear attenuation coefficients $\mu$, were determined from measurements, using a collimated beam of gamma rays from a Cobalt-60 source [6, 7].

\section{Method}

The linear attenuation coefficients of concretes have been measured using the gamma spectrometer system containing $\mathrm{NaI}(\mathrm{Tl})$ detector. The measurements have been performed at photon energy of 1173 and $1332 \mathrm{keV}$, produced by Cobalt-60 radioactive source $[6,7]$.

The linear attenuation coefficient varies with photon energy, type of material, and physical density of material. The attenuation of photons is mathematically based on the following formula:

$$
\frac{I}{I_{0}}=e^{-\mu \chi}
$$

Here, $I_{0}$ is gamma-ray intensity at zero absorber thickness, $I$ is the gamma-ray intensity transmitted through an absorber of thickness $x, \mu$ is the linear attenuation 
coefficient. The values of TVL and HVL thicknesses are given by Eq. 2 and Eq. 3, respectively.

$$
\begin{aligned}
& H V L=X_{h}=\frac{\ln 2}{\mu}, \\
& T V L=X_{t}=\frac{\ln 10}{\mu} .
\end{aligned}
$$

The concept of HVL and TVL is very useful in doing rapid, approximate shielding calculations [8]. Measured linear attenuation coefficients of different densities of concretes are shown in Table I for different gamma energies.

\section{TABLE I}

Measured linear attenuation coefficients.

\begin{tabular}{c|c|c|c|c}
\hline \hline $\begin{array}{c}\text { Concrete } \\
\text { Types }\end{array}$ & $\begin{array}{c}\text { Density } \\
{\left[\mathrm{g} \mathrm{cm}^{-3}\right]}\end{array}$ & $\begin{array}{c}1173 \\
{[\mathrm{keV}]}\end{array}$ & $\begin{array}{c}1332 \\
{[\mathrm{keV}]}\end{array}$ & References \\
\hline LC & 1.484 & 0.101 & 0.09 & {$[6]$} \\
SLC & 1.869 & 0.115 & 0.109 & {$[6]$} \\
OC & 2.46 & 0.174 & 0.165 & {$[6,7]$} \\
SHC & 2.953 & 0.175 & 0.167 & {$[6,7,9]$} \\
HC & 3.463 & 0.18 & 0.17 & {$[6,7]$}
\end{tabular}

Figures $1 \mathrm{a}$ and $1 \mathrm{~b}$ illustrate the linear attenuation coefficients of concretes with different densities for two gamma-ray energies of $1173 \mathrm{keV}$ and $1332 \mathrm{keV}$.
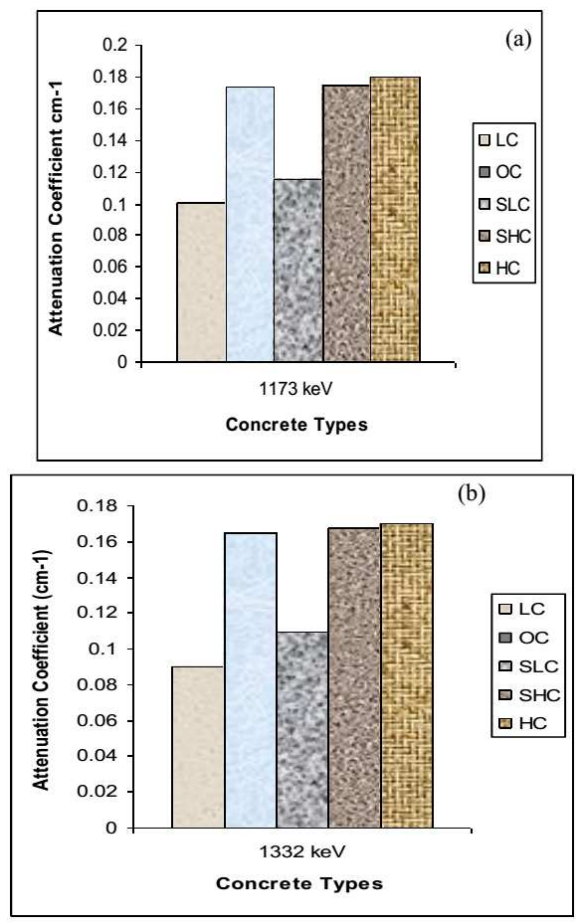

Fig. 1. Linear attenuation coefficients at (a) $1173 \mathrm{keV}$ and (b) $1332 \mathrm{keV}$.

\section{Results and discussion}

The purpose of radiation shielding is to reduce the effective equivalent dose from a linear accelerator outside the room to a sufficiently low level, one that is determined by individual states. This level is generally $0.02 \mathrm{mSv}$ per week for a public or uncontrolled area [10]. The HVL and TVL are defined as the thickness of a shield or an absorber that reduces the radiation level by a factor of one-half and one tenth of the initial level respectively and they can be defined in terms of the effectiveness of $\gamma$-ray shielding $[11,6]$. The amount of radiation that penetrates through a specific thickness of material is determined by the energy of the individual photons and the characteristics (density and atomic number) of the material. Half value layer (HVL) is the most frequently used quantitative factor for describing both the penetrating ability of specific radiations and the penetration through specific objects. When HVL and TVL values are known, the penetration through other thicknesses can be easily determined [5].

TABLE II

Calculated HVL and TVL thickness.

\begin{tabular}{c|c|c|c|c}
\hline \hline Concrete & \multicolumn{2}{|c|}{$1173(\mathrm{keV})$} & \multicolumn{2}{c}{$1332(\mathrm{keV})$} \\
\cline { 2 - 5 } Types & HVL $(\mathrm{cm})$ & TVL $(\mathrm{cm})$ & HVL $(\mathrm{cm})$ & TVL $(\mathrm{cm})$ \\
\hline LC & 6.86 & 22.79 & 7.70 & 25.58 \\
SLC & 6.03 & 20.02 & 6.36 & 21.12 \\
OC & 3.98 & 13.23 & 4.20 & 13.95 \\
SHC & 3.96 & 13.15 & 4.15 & 13.78 \\
HC & 3.85 & 12.79 & 4.08 & 13.54
\end{tabular}

Calculated HVL and TVL values for different densities of concretes are shown in Table II and in Fig. 2 for two values of gamma-ray energy.

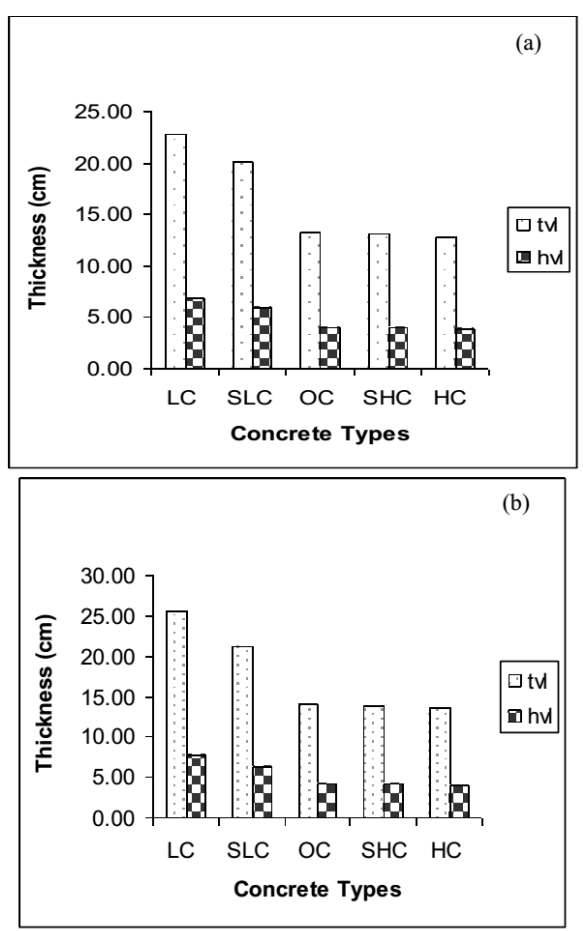

Fig. 2. HVL and TVL thickness at (a) $1173 \mathrm{keV}$ and (b) $1332 \mathrm{keV}$. 
It is clearly seen from Fig. 3, that the linear attenuation coefficient increases with the increasing density of the concretes and when attenuation coefficient increases, the HVL and TVL values decrease for both gamma energies. These results are supported by other reports $[3,4,7,9]$.

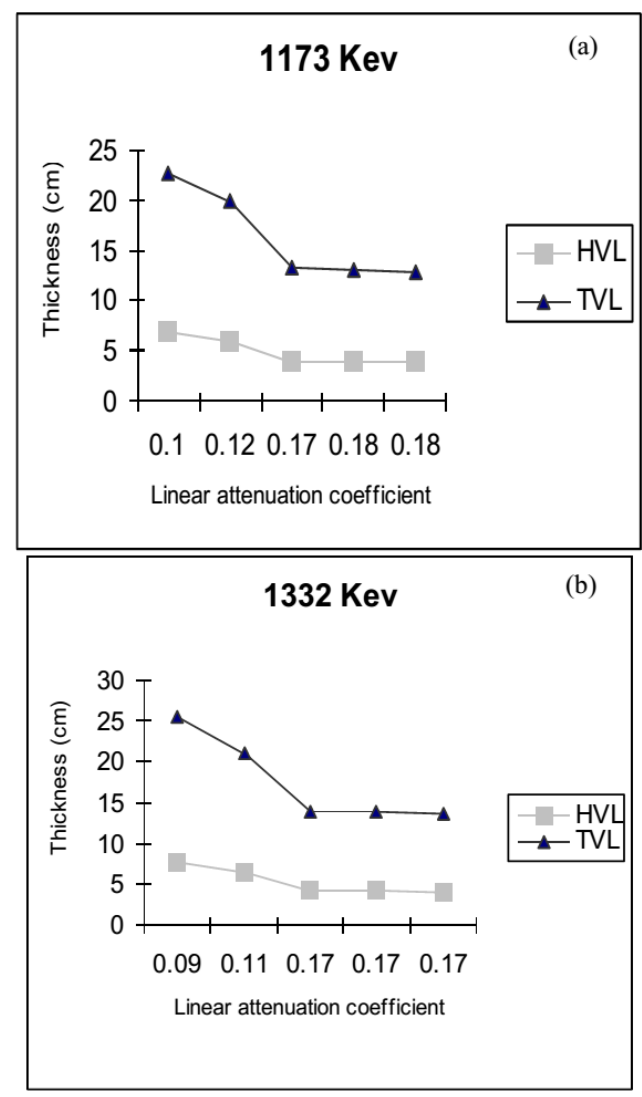

Fig. 3. Relation of HVL and TVL with $\mu$ at (a) $1173 \mathrm{keV}$ and (b) $1332 \mathrm{keV}$.

The most common materials used for shielding are ordinary concrete, barite concrete, high-density concrete, steel, and lead [9]. Some materials like lead have high density, which makes them suitable for shielding against gamma radiation. When working with multiple types of radiation, such as gamma radiation, there is a requirement for an additional shielding material or it is sometimes necessary to shield with several materials, because choosing of shielding material and determined thickness of shielding material are dependent on photon energy. It is indicated that HVL and TVL are the most frequently used quantities for describing both the penetrating ability of specific radiations and the penetration through shielding materials [5]. While, the HVL and TVL values of some material like lead, barite and ordinary concrete are available in the literature $[8,12,13]$, the information for different densities of concretes is not available.

\section{Conclusions}

Efficiency of the shielding material depends upon the interaction energy and the thickness of material. Knowing HVL and TVL values helps to determine which material effectively reduces the radiation intensity. A good rule of thumb: shield the less penetrable radiation type first then proceed to shield the more penetrable type. Instead of using attenuation coefficients to perform shielding calculations, we can use HVL and TVL values. It can be concluded from this work, that HVL and TVL values for concretes with different densities were calculated for energies of $1173 \mathrm{keV}$ and $1332 \mathrm{keV}$. It is shown that with the increasing density of the concretes, the HVL and TVL values decrease. It is suggested that the effect of multiple energy photons can be minimized by increasing shielding material density, indirectly reducing the materials' HVL and TVL thickness.

\section{References}

[1] S. Vallabhajosula, Molecular Imaging: Radiopharmaceuticals for PET and SPECT, Springer Science \& Business Media, 2009, p. 392.

[2] NCRP Radiation Protection in Educational Institutions, National Council on Radiation Protection and Measurement, Report No. 157 (2007).

[3] F.A. Ikraiam, A. Abd El-Latif, A. Abd El-Azziz, J.M. Ali, Arab J. Nucl. Sci. Appl. 42, 287 (2009).

[4] I. Akkurt, C. Basyigit, A. Akkaş, S. Kılınçarslan, B. Mavi, K. Günoglu, Acta Phys. Pol. A 121, 138 (2012).

[5] P. Sprawls, The Physical Principles of Medical Imaging, 2nd ed., Aspen Publication, NY, USA, 1993.

[6] I. Akkurt, K. Günoglu, C. Basyigit, A. Akkaş, Acta Phys. Pol. A 123, 374 (2013).

[7] I. Akkurt, H. Akyıldırım, B. Mavi, S. Kılınçarslan, C. Basyigit, Ann. Nucl. Energy 37, 910 (2010).

[8] A. Martin, S. Harbison, K. Beach, P. Cole, An Introduction to Radiation Protection 6E, CRC Press. Medical, 2012, p. 256.

[9] C. Basyigit, V. Uysal, S. Kılınçarslan, B. Mavi, K. Gunoğlu, I. Akkurt, A Akkaş, AIP Conf. Proc. 1400, 232 (2012).

[10] J.P. Biggs, Radiation Shielding for Megavolt-age Photon Therapy Machines 52nd Annual Meeting, AAPM, Philadelphia, 2010, p. 5.

[11] P.O. López, G. Rajan, E.B. Podgorsak, Radiation Oncology Physics: A Handbook for Teachers and Students, Chapter 16: Radiation Protection and Safety in Radiotherapy, International Atomic Energy Agency, 2005, p. 600.

[12] Sh. Sharifi, R. Bagheri, S.P. Shirmardi, Ann. Nucl. Energy 53, 529 (2013).

[13] P. Papagiannis, D. Baltas, D. Granero, J. PérezCalatayud, J. Gimeno, F. Ballester, J.L.M. Venselaar, Med. Phys. 35, 4898 (2008). 